\title{
Difficulties Facing English Teachers in Teaching Literary Texts at Higher Secondary Level in Bangladesh
}

\author{
Khandoker Montasir Hassan ${ }^{1}$ \\ ${ }^{1}$ Institute of Modern Languages (IML), Jagannath University, Dhaka-1100, Bangladesh \\ Correspondence: Khandoker Montasir Hassan, Associate Professor, Institute of Modern Languages (IML), \\ Jagannath University, Dhaka-1100, Bangladesh.
}

Received: July 11, 2018 Accepted: August 8, 2018 Online Published: August 22, 2018

doi:10.5539/ells.v8n3p15 URL: https://doi.org/10.5539/ells.v8n3p15

\begin{abstract}
The present Study examines the difficulties facing English teachers in teaching literary texts in English for Today (11-12) textbook which has been prescribed by the NCTB (National Curriculum Textbook Board) of Bangladesh from the academic session 2015-2016. Literature has always been an integral part of teaching foreign languages. In the era of CA (Communicative Approach), the aim of reading literature has been changed. From this view point, in July 2015, the NCTB has published a new version of English textbook for classes XI-XII, and included some literary texts in this book. The emphasis of these literary texts is not just on content but on the exploitation of the texts to trigger a variety of language activities. Based on a semi-structured interview with six HSC (Higher Secondary) level English teachers from four colleges of Dhaka city, this study particularly focuses on the newly included literary texts to critically evaluate the effectiveness of the materials; and identifies the difficulties that the teachers may encounter. Finally, some recommendations are drawn by means of valuable opinions of the participants.
\end{abstract}

Keywords: CA (communicative approach), EFL (English as a foreign language), literary texts

\section{Introduction}

As one of the most predominant language teaching approaches, the CLT has developed and expanded for over thirty years since its initial appearance in ESL (English as a second language) countries in the 1970s and during this time numerous attempts have been made to introduce the CLT to EFL contexts. In fact, "the Communicative Approach (CA) soon became a buzzword and took the whole ELT world by storm" (Barman \& Basu, 2013, p. 99). In case of Bangladesh before 1996, English was long taught as a compulsory subject from class-I to class-XII and for the language teaching method, ELT practitioners followed the Grammar- Translation Method (GTM). As the previously used method i.e. the GTM proved ineffective in teaching students to use English as a means of communication and "cosequently the general feeling has been that the urgent measures were needed to reverse the decline in English standards, and to meet a critical need for curriculum reform and teacher development" (Rahman, Kabir, \& Afroze, 2006, p. 3). Thus, like other EFL countries, the EFL teaching in Bangladesh has been undergone a significant change and refinement since 2001. To keep pace with the global trend of teaching and learning English using the CLT, the Ministry of Education (MOE) in Bangladesh brought about a revolutionary change by introducing the CLT in the late 1990s as it felt that the age old language teaching tradition known as the GTM was not any longer up to the mark to achieve the desired goal of language learning (Mohibullah, 2013). A series of English text books English for Today from class-VI to class-XII were written. And, as a process of continuation, in 2001, the new English for Today textbook for XI-XII has been introduced at the HSC level. The book has been guided by the principle of learning a language by actually practicing it through the four language skills of speaking, listening, reading and writing.

Since the inception of CLT in Bangladesh, a number of repeated attempts have been taken and steps are constantly being made to improve and modify the teaching and learning of English and as a part of these development efforts, the most recent attempt at ELT curriculum change is the publication of the new version English textbook for classes 11 and 12 from the academic session 2015-2016. Regarding the objectives and teaching approaches both the books are same: "the principle of learning a language by actually practicing it. This practice, which is carried out through the four language skills of speaking, listening, reading and writing, usually in an interactive mode, underlies the communicative approach to language learning" (Shahidullah et al., 2001; Billah 
et al., 2015). However, the only notable difference is the inclusion of some literary texts in it and the present paper intends to evaluate the suitability of those added literary texts.

Another important issue that there are some obvious challenges or problems that have been mentioned by the ELT experts and researchers to consider before teaching literature in a language classroom. Especially, when it is an EFL classroom of HSC level in a country like Bangladesh, the possibilities of challenges are more in comparison to other EFL settings. So, the present study also tries to probe into the issues including: the required language proficiency of the learners; selection of appropriate age group; the level of difficulty of the language i.e. the linguistic gap between the text and the everyday English that students are familiar with; the use of obsolete words and so on. In fact, there are some essential criteria that curriculum designers and researchers have mentioned to ensure while selecting the contents of a particular syllabus, like self-sufficiency; economy; significance; relevance to life; variety; suitability; validity; interest; utility; learnability and feasibility. To what extent these criteria are considered while selecting the literary contents of the present textbook is the area of critical evaluation of this paper. Finally, the major concern of the present study is to identify the difficulties that the Bangladeshi EFL teachers are facing while teaching these literary texts at the HSC level.

\subsection{Reasons for Using Literature in EFL Classroom}

As Leech (1996) states, "we generally suppose that the literature cannot be examined in any depth apart from the language, any more than the language cannot be studied apart from the literature" (p.1). In fact, literary studies deeply rely on linguistic study and from this viewpoint literature was initially the main source of input for teaching English in language classes in the era of GTM (Grammar-Translation Method). On the other hand, in the era of CLT (Communicative Language Teaching), literature was neglected and more attention was given to dialogues and conversations which were more practical and visible in the real world situation (Khatib et al., 2011). But, "since the middle of the 1980s increasing attention has been given to the possibility of teaching literature in ESL/EFL classes after a long period of neglect" (Duff \& Maley, 1991; as cited in Mate, 2005, p. 52) and the reasons for incorporating literary texts in language curricula have also changed over the last century. Now-a-days researchers in the field of ELT have emphasized the benefits of using literature for language teaching and learning purposes as Sage (1987) claims that "many teachers consider the use of literature in language teaching as an interesting and worthy concern" (as cited in Rahman, 2013).

However, the advantages of using literature in teaching and learning language are many and it is beyond the scope of the present paper to discuss all in detail. As the main focus of the paper is not to highlight the importance of incorporating literature in language classes rather to evaluate the suitability of the newly included literary texts in English for Today (XI-XII) text book and to identify the challenges or difficulties the EFL teachers are facing while teaching those texts in the classroom, the present researcher has listed only the main points/benefits identified from the review of a good number of related research studies as follows:

Authenticity;

Motivation;

Cultural/Intercultural Awareness and Globalization;

Intensive/Extensive Reading Practice;

Sociolinguistic/Pragmatic Knowledge;

Grammar and Vocabulary Knowledge;

Language Skills (Listening, Speaking, Reading and, Writing);

Emotional Intelligence (EQ) and Critical Thinking

(Carter \& Burton, 1982; Maley \& Moulding, 1985; Brumfit and Carter, 1986; Collie \& Slater, 1987; all cited in Khitab et al. 2011). The opinion of Carter and Walker, 1989 (as cited in Mate, 2005, p. 52) in this regard is very significant:

Today teaching language through literature is essentially viewed as teaching language through any other written material. Therefore, any standard activity that is used with non-literary texts such as re-writing, prediction activities, role-playing and so on can be used with literature as well (p. 52).

They, further, mention that the most important benefits of using literature are its ambiguities and indeterminacies that provide natural opportunity for discussion and different interpretations to be expressed, which is among the central goals of CLT. 


\subsection{Reasons for Incorporating Literary Texts in the English for Today XI-XII Textbook}

While identifying the difficulties in studying and teaching literature in traditional English departments in Taiwan,Chang (2003) remarks that many students experience extreme frustration and difficulty in literature courses and one of the most important reasons according to him is: "before entering English departments, students usually have not had much experience reading authentic literature written in English" (p.3).

At the tertiary level in Bangladesh, especially in the departments of English, the teachers experience the same types of difficulties as Farida and Sinha (2012) state: "students in Bangladesh who entered the English Departments faced great difficulty in tackling literature. These students lacked literary reading, foreign culture knowledge as well as appropriate linguistic competence" (p. 82).

Moreover, since the inception of CLT in Bangladesh in 2001 at HSC level, many research studies conducted in the related area in Bangladeshi EFL context have emphasized the importance of incorporating literary texts in the HSC English curriculum. Alam (2015) while evaluating the previous English for Today textbook, has stated: "the number of literary pieces in this coursebook is very few, and these literary works are hardly touched by both the teachers and students" (p. 10). And regarding the avoiding tendendency of literary texts, he has mentioned: "Due to the disparity between the contents of the text and the testing system, learners do not feel necessary to go through the literary contents" (p. 11).

According to Choudhury (1992) "the major problem in Bangladesh is with the contents of the textbooks; that the teachers follow cultural contents in the textbook which are very much foreign and do not allow the students to use their imaginative power." He also questioned the recent attempts to make English courses purely functional without any literary content. He has further mentioned, "teaching language without the help of literature is doomed to be unattractive and therefore, ineffective. Feeding on a mechanical diet can hardly be proper way to nurture young learner's mind." Besides research studies, columists, educationists and some university teachers from literaure backgrounds of the country have constantly expressed their disatisfaction regarding the absence of literary texts at secondary and higher secondary level English textbooks. Some of them even cosider it as one of the main reasons of student's deteriorating standards in English.

Perhaps based on these types of opinions of the researchers in favor of incorporating literature as well as considering the changing views of ELT experts regarding the use of literature in EFL classes, the NCTB has developed the new English Textbook for classes 11 and 12, especially by including a good number of literary texts from the academic session 2015-2015 after long fourteen years.

\subsection{The Objectives and Approaches of the Literary Texts in English for Today XI-XII Textbook}

The newly developed English for Today textbook for classes XI-XII, prescribed by the National Curriculum and Textbook Board (NCTB) from the academic session 2015-2016 has been designed according to the National Curriculum 2012. Basically, there is no basic difference between the objectives/learning outcomes of these two texts (present \& previous version of EFT text).

The book is based on the principle that has guided the writing of the English for Today books from class 6 onwards- the principle of learning a language by actually practicing it. This practice, which is carried out through the four language skills of speaking, listening, reading and writing, usually in an interactive mode, underlies the communicative approach to language learning (Shahidullah et al., 2001; Billah et al., 2015).

About the included literary texts, it is written, "Some literary texts have also been included. However, the emphasis in such cases is not on content but on the exploitation of the texts to trigger a variety of language activities (Shahidullah et al., 2001; Billah et al., 2015)."

So, the objectives and approaches of both the text books are same and the only difference lying is the size of the texts and cover. In the previous textbook (2001-2002) there were totally 24 Units, while in the new version (2015-2016) there were Fifteen (15) Units. Another, mentionable difference in the new textbook and which is also the main focus of the present paper is the inclusion of a large number of literary texts. Although, there were some literary texts in the previous textbook, the number was very few and those texts usually remained untouched both by the teachers and students due to the disparity between the HSC test and text. 
Table 1. List of the newly included literary texts in English for Today (2015-2016)

\begin{tabular}{|c|c|c|c|}
\hline Unit & Lesson & Genre & Title \\
\hline One & 2 & Speech & The Unforgettable History \\
\hline Two & 3 & Poem & The Traffic Police \\
\hline Two & 4 & Passage from a Film & "My Brother, the Traffic Policeman" \\
\hline Three & 2 & Short Story & The Luncheon- by William Somerset Maugham \\
\hline Four & 2 & Lyric from Play (Comedy) & Love and Friendship (Lyric from W. Shakespeare's As You Like It) \\
\hline Five & 3 & Poem & 'The Schoolboy-' by William Blake \\
\hline Six & 1 & Excerpts from Essay & "An Eastern University-" by Rabindranath Tagore \\
\hline Seven & 5 & Poem & 'Out, Out-’ by Robert Frost \\
\hline Nine & 1 & Poem & $\begin{array}{l}\text { 'I Have Seen Bengal's Face-'Translation of Jibanananda Das's } \\
\text { "Banglar Mukh Ami Dekhiyachi" }\end{array}$ \\
\hline Ten & 2 & Poems & $\begin{array}{l}\text { 'Dreams' - by D H Lawrence } \\
\text { 'Dreams'- by Langston Hughes }\end{array}$ \\
\hline Ten & 3 & An Abridged Version of A Speech & 'I Have A Dream-'by Martin Luther King Jr. \\
\hline Eleven & 2 & Article & Banglatown in East Lonon \\
\hline Twelve & 1 & Poems & $\begin{array}{l}\text { 'The Lake Isle of Innisfree-' by W B Yeats } \\
\text { 'September 1, 1939-' by W H Auden }\end{array}$ \\
\hline Twelve & 3 & Poem & 'The Charge of the Light Bridge-' by Alfred Tennyson \\
\hline Twelve & 4 & An Abridged Version of a Short Story & "The Old Man at the Bridge-" by Earnest Hemingway \\
\hline Fourteen & 1 & Poems & $\begin{array}{l}\text { 'She Walks in Beauty-' by Lord Byron } \\
\text { 'I Died For Beauty-' by Emily Dickinson }\end{array}$ \\
\hline
\end{tabular}

\subsection{Challenges and Criteria for Selecting Suitable Literary Texts}

Undoubtedly, the objectives and expected learning outcomes mentioned in the curriculum, especially about the included literary texts are conceptually valuable and all of them are literary masterpieces selected from the canon of British and American literature. But, as Alam (2010) states that not all pieces of literature are suitable for being used in language classroom. In fact, during the era of CLT in the early 1980s, literature was avoided in language classes. The reason of avoiding literature in language classes is clearly explained by Rivers (1968). He opines, "Study of literary movements and the literature of earlier centuries is best kept for students who wish to specialize in foreign literature at undergraduate or graduate level" (p. 231).

In support of using literature in language classes, the ELT experts claim that by studying literature, students are exposed to various cultures as well as various styles and levels of the target language, English. Rivers (1968) in this regard, mentions, "If cultural understanding is to be realized, the adolescent students must continue to read the thought and invention of his contemporaries, or such classical literature as is timeless in content and easily accessible in language" (p. 231). About the level of students' suitable for using literary texts for language learning, there are perceptions that literature may not be suitable at all levels with all learners as language of literature is often found to be very different from everyday kind of functional language. It is also claimed that background knowledge of Western history and culture that appreciation of English literature demands makes literature very challenging for non-native student learners.

Again, while many ELT experts consider authenticity as one of the most important benefits of using literature in EFL classes, Rivers' (1968) view is like this:

Even at advanced level of high school study, teachers will need to ensure that their students realize that what they read in fiction does not necessarily depict in faithful detail the reality of life for every individual in the foreign country. The ordinary life of an average citizen rarely provides the specific elements sought by the writer of a novel, play, or short story (p. 231).

Moreover, the ELT experts put forward some criteria to be considered while selecting any material for an EFL class. And, when it is about the selection of literary texts for a communicative classroom in an EFL context, it obviously requires more care and attention. For example, Lazar, (1993, cited in Alam, 2015) opines that "students' cultural background, their linguistic proficiency, literary background, length of the text, the text's exploiting ability and fitting with the syllabus must be considered before selecting the literary work in language classroom" (pp. 112- 113). Other researchers, for example, Collie and Salter (1987) also put forward more or less the same types of criteria to be considered before selecting any literary text for language classes like, literary text's ability to stimulate the learners' personal involvement and interest; texts relevant to life experiences, emotions, or dreams of the language learner. And, teaching and reading literature in language classes will 
definitely encounter difficulties, especially in EFL contexts, unless the above mentioned criteria are carefully considered before selecting the texts. However, in spite of the challenges; the benefits and justifications for incorporating literature in EFL classes are many and under these circumstances, if it is really possible to exploit literary texts in language classes and thus, enable the young learners in promoting critical thinking, analytical ability and intercultural awareness as well as benefit them in terms of developing communicative competence, why should we deny it.

\subsection{Statement of the Problem}

The objectives of the curriculum as well as the included literary texts have already been mentioned in the earlier section. As the main concern of this study is about the included literary texts and not the whole English curriculum, it is necessary to focus particularly on the learning outcome of the literary texts as mentioned in the NCTB English curriculum:

"Students will be able to read, understand, enjoy, interpret and critically appreciate stories, short plays, poems, and other literary pieces (reading, writing, speaking, listening)" (English Curriculum for Eleven \& Twelve, p.26).

Now, the questions that obviously require attention are: "How will we know whether the students have achieved it?" And, more specifically, how to determine whether the above mentioned claim is justified? It is true that only two years have passed since the present English for Today (2015-2016) textbook has been introduced and one may say that it is too early to measure the success of this new textbook and the effectiveness of the included literary texts. The only observable and measurable outcome so far is the HSC Final Examination Result-2017.

"Combined pass rate in HSC and equivalent examinations fail to its 10-years low while the number of Grade Point Average (GPA) 5 achievers came down to its seven-year low" (Alamgir, 2017, p. 1). This year's result is 5.79 percent lower than that of last year. So, from the HSC Result of 2017, it is found that this year's pass rate (66.84 percent) is the lowest since 2008, except the year 2015, when the success rate was 65.84 percent. Different national dailies of the country have tried to analyze the result for identifying the reasons behind this shocking fall in both pass rate and number of GPA-5 achievers this year. From their reports it is revealed that along with some other reasons, one of the most important reasons of this shocking fall is due to the poor performance in English. Even the lead news of The Daily Star on July 24, 2017 was "Poor show in English does the damage."

Students performed badly in English, said the Chairmen of several boards. According to data provided by the boards, more than 2.17 lakh students failed this subject alone. In Dhaka board, the success rate in English came down to 76.66 percent from the last year's 86.46 percent. The pass rate in English in Jessore board this year shows a fall of 17 percentage points." "English has always been considered the major factor in results. Many students flunked this subject, pulling down the tally of total students passed, said Prof. Mahabubur Rahman, Chairman of Dhaka board (Poor show in English, 2017, pp.1-2).

The Daily Prothom Alo identified four specific reasons behind this significant fall: "i) the introduction of a new evaluation method; ii) shocking performance of students of Comilla Board;

iii) Students' poor performance in English especially in four education boards; and, iv) a large number of students' poor performance in MCQ questions" (Ahmed, 2017, pp.1-2). Another significant aspect of this year's HSC Result is the startling low pass rate of students under Comilla board which ultimately pushed down the overall pass rate. Only 49.53 percent students came out successful causing this board to be at the bottom of the result chart. A little over 1 lakh student took part in the exams and only 62 percent of them passed English, according to the data.

While analyzing the reasons of poor performance in English, Professor Md. Ruhul Amin Bhuiyan, principal of Comilla Government Women's College said that due to the question paper of the English first paper in the new curriculum this year, the rate of drop is very high. In a short time, the students could not acquire the new syllabus, and teachers could not complete the education as well (Rahman, 2017).

Under these circumstances the questions that obviously come in to our concern are: To what extent the included literary texts appropriate for HSC level students. Are the texts suitable enough in terms of difficulty and the students' level of language proficiency? Do the curriculum designers consider the criteria proposed by the ELT experts like context, culture, linguistic difficulty, demand of background knowledge, students' language proficiency etc. before selecting the literary texts? Are the activities or exercises sufficient enough to ensure effective language learning? Or, whether there exists any necessity to make any change in existing literary texts. 
This is because out of 57 lessons under 15 units, the literary texts constitute about 20 lessons of the English for Today textbook.

And the justification for the present study actually came from these above mentioned concerns regarding the shocking performance of the HSC level students in English and when more than 2.17 lakh students failed in English alone just after the changing of the EFT after long 14 years.

\subsection{Objectives and Research Questions}

The purpose of the study is to identify the difficulties facing English teachers in teaching the literary texts in English for Today XI-XII Textbook and to propose some suggestions based on the valuable opinions of the EFL teachers teaching at HSC level emphasizing the effectiveness of the included literary texts in the present textbook in respect of achieving curriculum objectives.

Thus, the present study aims to:

i. Identify the difficulties facing English teachers in teaching the literary texts in English for Today XI-XII Textbook;

ii. Evaluate the effectiveness of the literary texts included in English for Today XI-XII textbook in respect of achieving curriculum objectives.

\subsection{Research Question}

i. What are the difficulties facing English teachers in teaching the literary texts in English for Today XI-XII Textbook?

ii. To what extent are the literary texts consistent with the CLT in respect of achieving curriculum objectives and prescribed approaches mentioned in English for Today XI-XII Textbook?

\section{Research Design}

To serve the purpose of the study, a qualitative research methodology was chosen. Semi-structured interview was conducted by the researcher to investigate teachers' opinions based on primary themes coherent with the research questions of the study that included the difficulties EFL teachers are facing in teaching the literary texts in English for Today XI-XII Textbook and the consistency of these literary texts with the CLT in respect of achieving curriculum objectives.

\subsection{Profile of the Participants}

All the teachers involved in the study were non-native speakers of English teaching HSC level students at three non-government and one government colleges of Dhaka city including Mirpur College, Hazrat Shah Ali Girls' College, Tongi Government College and Notre Dame College. All of the participants completed M.A. in English from public universities of Bangladesh. For the purpose of observing research ethics, the names of the participants were kept secret. Thus, the six participants were given pseudonym name as T 1, T 2, T 3, T 4, T 5 and $\mathrm{T}$ 6. The demographic information of the participants is as follow:

Table 2. Demographic Information of the participants

\begin{tabular}{llllllll}
\hline SL & Teachers Description & \multicolumn{7}{l}{ Teachers Status } & & \\
\hline 1 & General Characteristics of the Participants & T1 & T2 & T3 & T4 & T5 & T6 \\
2 & Sex & M & M & F & M & M & M \\
3 & Teaching Experience & 11 & 12 & 13 & 08 & 12 & 10 \\
4 & No. of Classes Per Week & 12 & 13 & 16 & 14 & 16 & 17 \\
5 & Class Size (No. of Students) & 75 & 75 & 85 & 120 & 75 & 90 \\
6 & Training in teaching methodology & No & No & No & yes & No & No \\
\hline
\end{tabular}

\subsection{Instrument}

The format of the interview was semi-structured and teachers were encouraged to explain their views in detail. The interviews were conducted with prompts whenever necessary; and they were conducted in English and Bengali; and hence the language in which all the participants would most likely feel comfortable communicating. All the six interviews were conducted one time per participant and lasted around 30 minutes. The interviews were audio-recorded with participants' consent as well as backed up by taking notes of the key information in order to carefully review the data provided by the interviewees. 


\subsection{Data Analysis and Organizing the Data}

While conducting the interviews, sometimes some questions were changed depending on the direction of the interview and the natural flow of the questions was ensured depending on the individual interview's answers. Taking advantages of a semi-structured interview, sometimes the researcher probed deeper into the discussion to know the views and opinions of the interviewees. However, the interview consisted of open ended questions were free from any bias of the researcher.

The interview questions were formulated carefully by the researcher so that there was no unique socially acceptable answer but the teachers were asked to think before answering and focus on their own views, experiences and identified problems. Along with demographic information like the basic teaching background of the teachers; their weekly workload and average class sizes (mentioned in the table section- 2.1.), the key points that all the participants were asked to answer were:

- Their reaction or opinion about the changes of the HSC English textbook, particularly focusing on the included literary texts;

- The difficulties they were facing while teaching those texts and the students' reactions/feedback;

- The teachers' opinions about the effectiveness of those texts by exploiting them successfully for achieving communicative competence;

- Concerns over the exercises and question items based on the literary texts to measure the communicative competence of the learners;

- Desires for changes or modification.

The provided data of the recordings on the above mentioned key points were at first transcribed and the transcriptions were then analyzed to identify common themes. However, the identified themes have been presented as report in the following sub-sections:

(a) Attitude towards the new English for Today XI-XII Textbook (2015-2016) and the Included Literary Texts in It;

(b) Difficulties and challenges in teaching literature at HSC level and Students' Feedback:

(c) CLT and Its Consistency with the Literary Texts and Exercises

(d) Concerns over and Assessment Procedures

(e) Desires for Changes or Modification

\section{Discussion and Summary of Findings}

All the six teachers reported that they were facing problems in teaching the texts.

During the interviews, all six participants mentioned the problems common in teaching literature were:

I) All experienced the language in those texts as difficult. The difficult language and unfamiliar culture-related elements in the texts as sources of difficulty in literature studies; and two out of the six participants (T3 \& T6) explicitly said that it was extremely difficult.

II) More problems with poetry as a genre. While reading the texts, the notebook's or guidebook's Bengali translation was used by the students to understand and it created problems for them especially in case of reading and understanding English poetry as poetry does not usually contain plot elements like fiction does. As a result for most of the students, reading poetry means memorizing the critical appreciation available in note books."- T2

III) Experienced various difficulties in constructing literary understanding: lack of language competence, lack of ability to read independently or to see the deeper meaning. Students had been frustrated in reading the literary texts and were bored by them.

IV) Gap between Test and Text: For the final exam, they were supposed to answer only one item of 08 marks purely based on literary texts: Appreciating short stories/ poems (identify theme, subject-matter and interpretation)

V) Students' lack of English language proficiency to deal with the texts; they try to understand all the words and did not help them make sense in case of poetry.

Some units contain two poems which they think unnecessary; like Unit-14, to describe ideas about beauty and truth lesson-1 includes two poems 'She Walks in Beauty-' by Lord Byron and 'I Died For Beauty-' by Emily 
Dickinson; Unit-10, Lesson-2 includes two poems: The Lake Isle of Innisfree-' by W B Yeats and 'September 1, 1939-' by W H Auden.

VI) Some poems are too long 'The Charge of the Light Brigade-' by Alfred Tennyson.

VII) English proficiency of the students affected not only the reading of literary texts but also writing about them. Even when they understood something in the text, some of the students reported having difficulty in writing coherently.

VIII)Students' lack of interest, lack of competence, inability to understand, lack of motivation and so on.

Some of the important opinions of the participants selected from the analysis of the recorded transcription are given below:

1) Regarding their attitude towards Curriculum Objectives/Learning Outcomes and Language Assessment Procedures:

All the six participants expressed almost same opinions that there was a huge gap/mismatch between objectives of the text and assessment procedures. They opined "Included exercises in the textbook are not sufficient, they don't reflect curriculum objectives. Moreover, the test items in the HSC examination discourage the learners to read, understand, and enjoy the literary texts. Even there is no provision in the assessment as well as in the exercises to develop listening and speaking." And, that's why these literary works are hardly touched by the students.

2) About Changes or Modification of the Literary Texts

Four Teachers Replied, "All the literary texts should be changed", T3 opined that the texts should be modified by excluding some poems and difficult texts and adding some new ones. Only T4 said: Although the texts are difficult, it should remain unchanged.

When he was asked a follow-up question, "Why did he think so?"

T4 Replied: "The previous text was too easy for many students and it was not a standard textbook. The present one is alright. Some texts are difficult for the students but it is the responsibility of the teacher to make them understand. Initially it is creating problems as the teachers are not well-trained and habituated in teaching these types of materials in language classes."

About the Replacement of the Literary Texts, Types of Problems They Faced and Their Suggestions T1 and T2's Replies were like this:

TI: "The whole text should be modified, and in case of literary texts, the texts that are very easy to understand especially the vocabulary, should be selected for HSC students."

T2: "Instead of old literary texts, new or contemporary writers' texts should be selected. Why do you need to teach a lyric from Shakespeare that contains archaic words like "Thou" "Thy" "Heigh-ho" "Dost"? He asked.

Isn't there any other lyric to make them understand Personification and Rhyming? " He questioned.

He continued, "Essays like Tagore's An Eastern University, the text of Unit-10, Lesson-1 entitled What is Dream basically deals with Freud's theory of dream. Can the HSC level learners hold interest on such topics?

TI: "In comparison to the previous text book, the present textbook is very difficult, especially the language or vocabulary. It is very tough for the HSC level students to understand. It may be easy for the best institutions and best students. The present text book as well as the literary texts is not suitable for HSC level students."

Regarding the types of the problems he was facing, T1's reply was:

"Sometimes I tried to practice Group-work by dividing the students in different groups and ask them to read but failed as most of the time the students gossip with each other in Bangla, asks me that they don't understand anything." (T1)

After this reply, when he was asked a follow-up question, "How do you teach them?"

T1 replied: "At first I myself read the original text in case of the abridged version e.g. Gulliver's Travels, and then tells the class about the summary to help them understand the context, although, it is very difficult in large classes."

The next follow-up question was: "How do you teach the poems?" 
"I just recite and translate it in Bengali. In fact, students only memorize the summaries or themes of the poems from the guidebooks or note books which are sufficient to answer the questions at HSC final examinations. So, they are not very much interested in reading the poems in the classes." T1 answered.

"Some stories like The Luncheon (Unit-3, Lesson-4) are alright, but still there are some problems. For example, at the very beginning of this lesson - Warm up activity: Discuss in a group:

What is a short story? What are some essential elements of a short story?" How do they know that?

T2: "If the whole textbook is not changed the result will be more disastrous in future. Don't you see the passing rate in English this year?"

When he was asked a supplementary question, do you think, it is because of these literary texts?

He replied: "Not fully but to a large extent."

Why do you think so?

T2: This year most of the students obtained poor marks in English First Paper in comparison to Second Paper. But, in the previous years, the result was just the opposite.

When he was asked about his suggestions, T2 mentioned two important points: i) teachers' training and, ii) the literary texts should be totally replaced by some easy and interesting texts that stimulate learners personal involvement with sufficient number of useful exercises consistent with curriculum objectives and CLT principles. The texts that are related personal experiences, feelings and emotions.

\section{Recommendations and Conclusion}

\subsection{To Evaluate the Effectiveness of the Literary Texts especially in Terms of Linguistic Difficulty and Demand} on Background Knowledge

The first and foremost necessity is to evaluate the effectiveness of these literary texts immediately. This evaluation can be conducted in many ways. For example, checklists are instruments that help teachers or researchers in the area of ELT to evaluate the teaching-learning materials like textbooks. Other research methods like interview (formal \& informal; structured \& semi-structured); Focused Group Discussion (FGD) etc. should be conducted involving the HSC level teachers and thus identify their opinions about these literary texts; classroom observations to know the actual classroom scenario and students' feedback about the literary items.

\subsection{Needs Analysis}

Needs Analysis is a mandatory prerequisite before designing and producing any curriculum. So, the present study stresses the importance of conducting a rigorous needs analysis including the HSC level teachers as the repodents to collect the actual information from their real classroom experiences.

\subsection{Considering the Issues of Context and Culture}

As it is believed by the ELT experts and researchers, now-a-days, that one methodology developed and effective in one context will not necessarily be efficient and effective in another context. Especially when the country is like Bangladesh, problems like social and cultural constraints must be taken into consideration in the way to successful implementation of the CLT. As Brman and Basu (2013) state, "In ELT context refers to the socio-cultural, political, demographic and economic conditions, in which language education takes place. Contexts around the world are diverse and language educators need to be sensitive to the particular demands and needs of the learners" (p.191). The same is true in case of selecting literary texts.

\subsection{Including Appropriate and Sufficient Exercises with the Literary Texts}

The kinds of classroom activities that best facilitate learning in CLT classroom should be included in exercises. More detailed lesson plans and teaching procedures should be included with the texts.

\subsection{Minimising the Gap between the Text and HSC Test}

In case of Bangladesh, the trend is that if the contents of the textbook are not included in the final exams both the students and teachers do not feel any interest to go through the contents. The students' as well as teachers' and guardians' main purpose of language learning is still to achieve a good score and not to achieve language proficiency. This is the reality. So, there must be a coherent relationship between the HSC assessment system and the included literary texts of English for Today so that both the teachers and students feel essential to go through the literary contents attentively and appropriately. 


\subsection{Selecting the Appropriate Genre/Choosing Appropriate Text}

"One criticism of using literature in the EFL classroom deals with the overuse of what is called the traditional canon- those famous, classic, award winning literary texts that often contain language that is difficult for a learner to comprehend" (Van, 2009, p. 3).

Thus, considering the linguistic proficiency and the present competence level of the students; length of the text; the texts exploiting ability and fitting with curriculum objectives; vocabulary; literary text's ability to stimulate the learners' personal involvement and interest; texts' relevance to life experiences, emotions, or dreams of the language learner, the appropriate genre of literature should be selected. In fact, for HSC level students it is better to select those types of literary texts that are neither too easy nor too difficult. Easy poems and short stories that require students' personal exploration and thus, to unfold their latent talents and creativity should be included. In this regard, considering the proficiency level of our students, even some stories from children's literature can be selected. As Ghosn (1997, cited in Barman \& Basu, 2013, pp.248-249) clarifies that "children's literature, in comparison to adult literature, has simpler language, fewer lengthy stories, fewer abstract ideas, less complicated themes and offers just as wide as a variety of stories." However, care should be taken so that the quality and level of difficulty should not be below the standard.

\subsection{Skill Based Texts}

Texts that help developing writing, speaking as well as listening, reading should be selected. However, while using literature in the language classroom, skills should never be taught in isolation but in an integrated way and teachers should be trained properly to implement this principle of teaching literature in language classes.

\subsection{Teachers' Role}

Teachers should shift from the traditional teaching methods to the communicative approach. They have to forget the ways they were taught literature in their honours and masters classes. Their authoritative nature should be changed. They should be aware of the curriculum objectives mentioned in the preface of the text. To achieve the learning outcome, a teacher's role is the most important factor. Only a careful preparation; selection of teaching techniques and dedication are the requirements to exploit literature in an HSC level EFL class of Bangladesh.

\subsection{Teachers' Training}

How important or effective the syllabus is; how appropriate the text is; it is the teachers who will implement it in the classroom. Unless the teachers are well-trained, all initiatives will go in vain. From this view point, teachers training should be given the highest priority. Immediate steps should be taken by the NCTB to arrange training courses, training sessions, workshops and micro-teaching courses to train the teachers not only how to teach literature but also how to teach literary texts in Bangladeshi EFL classroom context. It obviously requires enough time to train all the teachers and that is why by this time, at least, Teachers Guide (TG) with detailed lesson plans and guidelines for every lesson should be provided immediately. A complete success of anything depends on proper planning prior to implementation. In case of Bangladesh, the last significant point that is totally neglected is the monitoring. As a result, most of the teachers complete their training but returning to their classroom they do not implement what they have learnt from their training.

Undoubtedly, using literature in EFL classes is very challenging and in case of Bangladesh at HSC level, one may find it an ambitious and aristocratic idea as well. It needs to find out immediately whether there exists any necessity to make any changes or modification or replacement of the existing literary texts. Otherwise, without ensuring these issues prior to teach literature in EFL classes, the inclusion of the literary texts in English for Today textbook for classess 11 and 12 will bring nothing but catastrophe.

\section{References}

Afroze, R. K., \& Rahman, A. M. M. H. (2008). English teachers' classroom practices in rural secondary schools: An exploration of the effect of BRAC training. Bangladesh Education Journal, 7, 7-16.

Ahmed, M. (2017, July 24). Char karone ebar fall kharap. Prothom Alo, pp.1-2.

Alam, M. M. (2015). Failure of exploiting literature in English for Today for developing language skills at the Secondary and Higher Secondary levels of education in Bangladesh: exploring reasons. Journal of Literature, Languages and Linguistics, 5, 8-13.

Alamgir, M. (2017, July 24). HSC pass rate falls to 10-year low. New Age, pp. 1-2.

Barman, B., \& Basu, B. L. (2013). Approaches and methods of language learning. Dhaka: Friends' Book Corner. 
Billah, Q., M., Alam, F., Shahidullah, M., Mortuza, S., Haider, Z., \& Roy, G. (2015). English for Today for Classes 11-12. Dhaka: National Curriculum \& Textbook Board.

Chang, H. S. (2003). Difficulties in Studying and Teaching Literature Survey Courses in English Departments in Taiwan. Unpublished Ph.D.Thesis, The University of Texas at Austin.

Chowdhury, S. I. (1992). English in Bangladesh (Bangla) in 'in and outside the garden'. Dhaka: Bidya Prakash.

Collie, J., \& Salter, S. (1987). Literature in the language classroom. Cambridge: Cambridge University Press.

English curriculum for Eleven \& Twelve. (2012). Bangladesh Ministry of Education.

Farida, N., \& Sinha, B. S. (2012). Introducing literature critically and creatively to Bangladeshi students. Proceedings of NELTA Conference 2012 (pp. 82-83). Kathmandu: Nepal.

Khatib et al. (2011). Literature in EFL/ESL Classroom [Electronic Version]. English Language Teaching, 4(1), 201-208. https://doi.org/10.5539/elt.v4n1p201

Leech, G. N. (1996). A linguistic guide to English poetry. New York, NY: Longman.

Mate, V. (2005). Teaching Shakespeare in the EFL Classroom. Retrieved from http://seas3.elte.hu/angolpark/Texts/VinceMate/VinceTeachingShakespeare.pdf

Mohib Ullah, M. (2013). CLT at the Higher Secondary level in Bangladesh:theory and practice. Journal of Education and Practice, 4(4), 197-206.

Poor show in English. (2017, July 24). The Daily Star, 1-2.

Rahman, M. (2013, November). Literature: An important mechanism for teaching language. The Guardian. Retrieved from http://www.theguardianbd.com/literature-important-mechanism-teaching-language/

Rahman, M. (2017, July 25). Pass rate in Comilla HSC exam falls sharply. The Daily Observer. Retrieved from http://www.observerbd.com/details.php?id=86061

Rivers, W. M. (1968). Teaching foreign-language skills. Chicago, IL: The University of Chicago Press.

Sahidullah, M., Islam, J., Majid, I. A. N., \& Shams, N. (2001). English for Today for Classes 11-12. Dhaka: National Curriculum \& Textbook Board.

Van, T. T. M. (2009). The relevance of literary analysis to teaching literature in the EFL classroom. English Teaching Forum, 3, 2-9.

\section{Appendix A}

\section{Interview Question List}

1. About your education.

2. What was your major in MA?

3. How long have you been teaching English at HSC level? How many classes do you take per week? What is the average number of students in your class?

4. Did you receive any pre-service or in-service training?

(If yes, follow-up questions, what type of training, how long and where)

In that training was there any section/technique that you learnt about how to teach literary texts in EFL/CLT classes?

5. I think you are familiar with the both HSC texts, the previous and the present one?

6. What is your comment/evaluation/opinion about the changes? Do you like the new text or the old one? Why?

7. Which textbook (the present/the previous one) reflect a communicative syllabus?

8. Perhaps you have noticed that one of the most important changes in the new text is the inclusion of many literary texts like: Speeches (2); Poems (including lyric, lyric from drama- As You Like It,) and total 14 poems; one translation of a Bengali Poet; Short Stories (The Luncheon; The Old Man at the Bridge); Excerpts from Essay "An Eastern University-" by Rabindranath Tagore and so on.

- What is your reaction? 
9. Do you face any problem in teaching the texts in your class? (If yes, follow-up questions: what types of problems? Do the students find it interesting in reading the texts? Do you feel comfortable in teaching the texts?)

10. Do you find problems with all types of literary texts or any particular genre?

11. What classroom activities do you usually do to develop communicative competence?

12. Can you give example?

13. How is your students' feedback on using literature to learn English?

Do they enjoy and understand?

14. What do you understand by the term "communicative"? Do you think the included literary texts reflect a communicative syllabus?

15. Do you think the question items based on literary texts are testing "communicative competence" of the learners?

16. "Some literary texts have also been included. However, the emphasis in such cases is not on content but on the exploitation of the texts to trigger a variety of language activities."

Do you think the included literary texts and the exercises reflect this aim?

17. Do you think the text should be changed /modified? If yes, do you have any particular suggestions?

\section{Copyrights}

Copyright for this article is retained by the author, with first publication rights granted to the journal.

This is an open-access article distributed under the terms and conditions of the Creative Commons Attribution license (http://creativecommons.org/licenses/by/4.0/). 